\title{
Synthesis of semiconductor oxide nanosheets, nanotetrapods and nanoplane-suite like grown on metal foil using different method
}

\author{
Marwa Abdul Muhsien Hassan ${ }^{1}$ Haidar Abdul Razaq Abdul Hussian ${ }^{1}$. \\ Mohamed O. Dawood ${ }^{1}$
}

Received: 7 November 2014/Accepted: 15 April 2015/Published online: 28 April 2015

(C) The Author(s) 2015. This article is published with open access at Springerlink.com

\begin{abstract}
ZnO}$ production nanostructure using different method: first method, electrochemical deposition on $\mathrm{Zn}$ foil using $0.3 \mathrm{M}$ zinc sulfate heptahydrate $\left(\mathrm{ZnSO}_{4} \cdot 7 \mathrm{H}_{2} \mathrm{O}\right)$ and sulfuric acid aqueous solution at a current density of 30 and $35 \mathrm{~mA} / \mathrm{cm}^{2}$ for deposition time $40 \mathrm{~min}$ at room temperature and second method, $\mathrm{Zn}$ foils were thermally oxidized in a conventional tube furnace at a temperature equal range of $700-900{ }^{\circ} \mathrm{C}$ in air for $5 \mathrm{~h}$ or less in static air to prepared semiconductor nanomaterials $\mathrm{ZnO}$ nanorods, nanotetrapods and nanoplane. The XRD diffraction of higher intensity peaks at (101) and (002) miller indices for two methods can be recognized to a hexagonal wurtzite structure unit cell. Surface morphology images with different magnifications which clearly shows that the whole $\mathrm{Zn}$ foil and rod substrate obtained $\mathrm{ZnO}$ nanosheets, nanotetrapods, nanorods and growth nanoplanes were also found. The length of these nanotetrapods and nanorods lies in the equal range of $1-1.5 \mu \mathrm{m}$ with an average diameter of $80 \mathrm{~nm}$. It was well known that $\mathrm{ZnO}$ nano crystal exhibited two emission peaks. One was located at about $365 \mathrm{~nm}$ wavelength (UV luminescence band), and the other peak position at $475 \mathrm{~nm}$ wavelength (green luminescence band).
\end{abstract}

Keywords $\mathrm{ZnO}$ nanotetrapods - FESEM ·

Photoluminescence $\cdot$ Electrochemical deposition .

Thermal oxidation

Marwa Abdul Muhsien Hassan

marwa_alganaby@yahoo.com

1 Physics Department, College of Sciences, Al-Mustansiriya University, Baghdad 00964, Iraq

\section{Introduction}

In recent years, there has been a great interest in production of transparent conducting oxide (TCO) and transparent oxide semi-conductors for the development of photonic devices and transparent conducting electrodes (TCE) for solar cells [1]. One-dimensional semiconductor nanostructures are expected to provide functional components for future electronic, optoelectronic, and nano electromechanical systems [2]. The wide direct band gap (3.37 eV) and large exciton binding energy $(\sim 60 \mathrm{meV})$ make zinc oxide $(\mathrm{ZnO})$ an excellent optoelectronic material [3]. $\mathrm{ZnO}$ based nanostructure research has drawn considerable attention in the last few years as a multi-functional material due to its versatile properties like near UV and visible (green, blue and violet) emission, optical transparency, electrical conductivity, piezoelectricity and many other promising applications in electroacoustic transducers, gas sensors, transparent conducting coating materials, photovoltaic devices and optical solar cells [4]. $\mathrm{ZnO}$ has also been confirmed as a promising functional material in other nanodevices such as field emitters and gas sensors. The synthesis of $\mathrm{ZnO}$ nanostructures is thus currently attracting intense worldwide interest. Numerous $\mathrm{ZnO}$ nanostructures have been demonstrated, for example, nanowires, nanotubes, nanobelts, nanopropellers, and nanocages [3]. It manifests its applications, especially when approaching the nanoscale size, for example, in the form of one-dimensional nanowires/nanorods/nanotubes or two-dimensional nanoplates/nanosheets, which have been widely accepted as the building blocks for nanodevices. In view of this, controlled growth of nanostructures in terms of size, shape, and orientation is a prerequisite, and a large amount of intensive research has been conducted to prepare desired $\mathrm{ZnO}$ architectures [5]. Various techniques have been 
adopted to synthesize $\mathrm{ZnO}$ nanostructures such as vapor transport process or physical vapor deposition (PVD), metalorganic chemical vapor deposition (MOCVD), microwave plasma deposition, hydrothermal synthesis and electrochemical deposition [6].

\section{Method section}

\section{First method}

A thick $\mathrm{Zn}$ foil $(99.96 \%$ purity and thickness $0.35 \mathrm{~mm})$ was cut into a square size of $1.5 \times 1.5 \mathrm{~cm}^{2}$ for conductive brass in the base holder of a Teflon cell. $\mathrm{Zn}$ foil samples were put into diluted hydrochloric acid $(\mathrm{HCl})$ to get rid of the surface oxide on the samples for $15 \mathrm{~min}$, respectively. Then, all the samples were ultrasonically cleaned in deionized (DI) water and polished using abrasive paper. $\mathrm{Zn}$ foil samples were mechanically surface-polished with abrasive papers starting from 240 and increasing to 400 , 600,800 and 1200 with diamond material. Intermittently after polishing with different abrasive papers, the surface was washed with deionized (DI) water to rinse off any particles generated while polishing. Ultrasonic cleaning in acetone, methanol and deionized (DI) water, respectively, for about $15 \mathrm{~min}$ was done after polishing to clean the surface more effectively and then dried with $\left(\mathrm{N}_{2}\right)$ nitrogen stream. After the mechanical polishing process was completed, the sample was put in a Teflon cell and it was prepared for the next electrochemical process. Before electrochemical deposition, the zinc samples were annealed at $350{ }^{\circ} \mathrm{C}$ for $2 \mathrm{~h}$ to remove the mechanical stress and to enhance the grain size, and then cooled in air at room temperature $30{ }^{\circ} \mathrm{C}$. The electrochemical cell contained $0.3 \mathrm{M}$ zinc sulfate heptahydrate $\left(\mathrm{ZnSO}_{4} \cdot 7 \mathrm{H}_{2} \mathrm{O}\right)$ and sulfuric acid $(\mathrm{pH}=3)$ aqueous solution liquid at a current density of equal range of ( 30 and $35 \mathrm{~mA} / \mathrm{cm}^{2}$ ) for $40 \mathrm{~min}$ at room temperature. A schematic diagram cell of electrochemical deposition for the zinc oxidation system consists of the electrochemical Teflon cell, two electrodes (cathode and anode), power supply (DC current), magnetic stirrer and multimeter for the process. These electrochemical processes were performed at room temperature $30{ }^{\circ} \mathrm{C}$. An anode was made from a brass plate to hold and to allow the current through the sample ( $\mathrm{Zn})$ and platinum mess foil was used to be a cathode as shown in Fig. 1.

\section{Second method}

Thick Zn foils and rods (99.99\% purity) with a thickness of $0.35 \mathrm{~mm}$. The samples were cleaned with $0.1 \mathrm{M} \mathrm{HCl}$, thoroughly rinsed with deionized water and then put in acetone for an ultrasound bath for $15 \mathrm{~min}$ to remove impurities and native oxide from the surface of the $\mathrm{Zn}$ metal surface. The sample was dried in $\mathrm{N}_{2}$ and then put into an oxidation chamber (tube furnace, two zone) made in Iraq.

Fig. 1 Setup experimental work

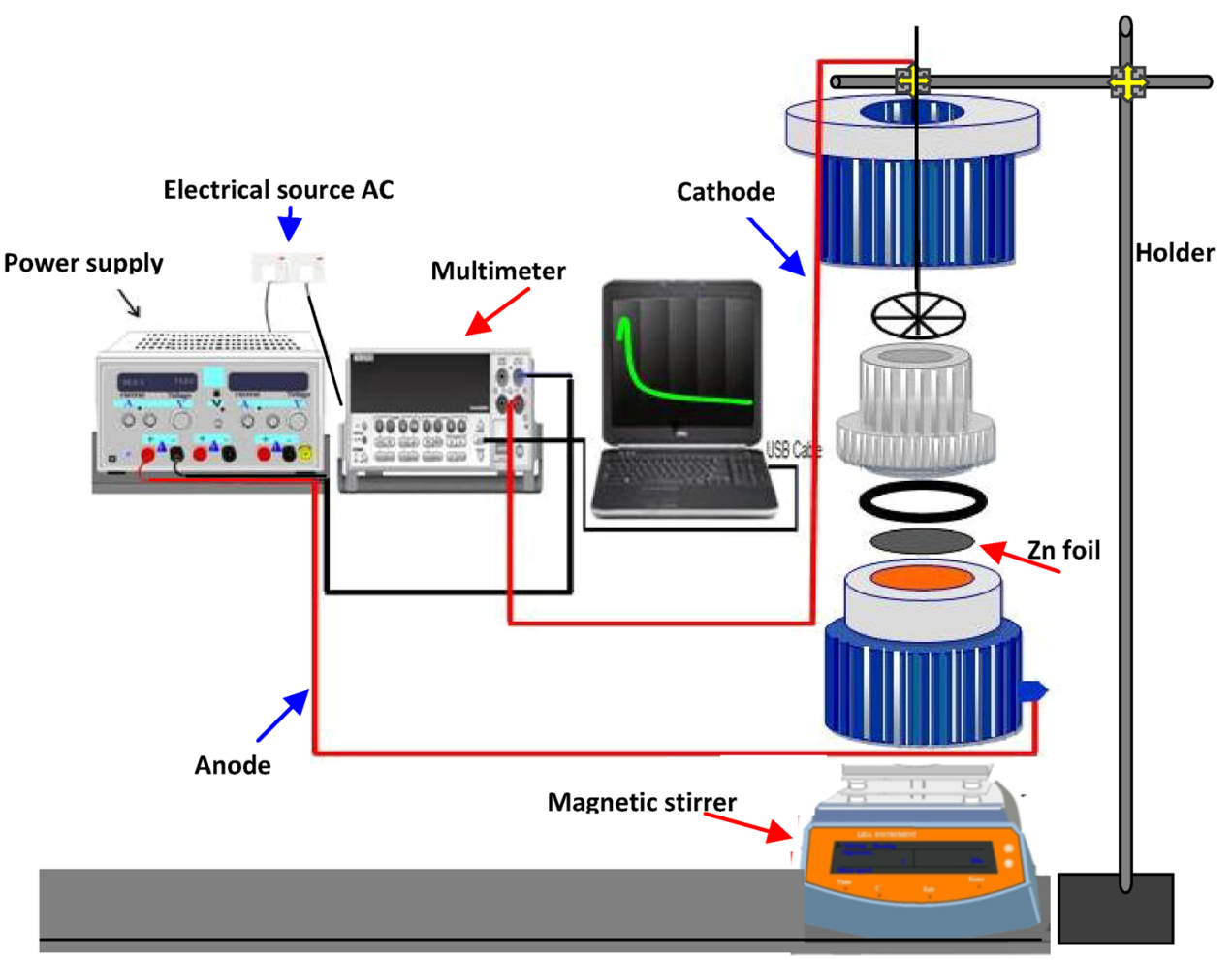


$\mathrm{Zn}$ foils and rods were thermally oxidized in a conventional tube furnace at a temperature of $700-900{ }^{\circ} \mathrm{C}$ in the air for $5 \mathrm{~h}$ or less in static air. The sample was then cooled down to room temperature $\left(30{ }^{\circ} \mathrm{C}\right)$. The crystal structures of the samples were investigated using X-ray diffraction (XRD, Philips PW 1050) technique with $\mathrm{Cuk} \alpha$ radiation $(\lambda=0.154 \mathrm{NM})$ in the $2 \theta$ range of $20^{\circ}-80^{\circ}$. The surface morphologies and components of the oxidized $\mathrm{Zn}$ were characterized using a scanning electron microscope (FESEM, Hitachi model S-4160, Japan-Daypetronic Company) in Tehran country.

\section{Results and discussion}

Figure 2 shows energy dispersive spectrometry (EDS); it can be seen only demonstrating the elements of $\mathrm{Zn}$ and $\mathrm{O}$, further confirms the high purity of $\mathrm{ZnO}$ nanomaterials and agreement with the $\mathrm{XRD}$ results, the element ratio of $\mathrm{Zn}$ to $\mathrm{O}$ is quantitatively calculated found to be equal 82.5:17.5 as shown in the inset in this figure below.

FESEM images with different magnifications of zinc oxide nanosheets grown on the $\mathrm{Zn}$ foil as shown in Fig. 3a, b. It was observed that the both currents used in this work (30 and $35 \mathrm{~mA} / \mathrm{cm}^{2}$ ), lead to generate nanosheet-like architectures, smoother and seems to be highly adherent to the surface of the metallic Zn foil substrate.

The morphology of the structures shows that the electrochemical deposition was done uniformly on the surface and created the granular structure in a nano-sheet shape. Large number of nanosheets distributed in all directions can be observed in Fig. 3a, and porosity was approximately
$75 \%$. The thickness of $\mathrm{ZnO}$ layers increased with increasing porosity.

Figure 4 shows the XRD patterns of $\mathrm{ZnO}$ prepared using electrochemical deposition grown on $\mathrm{Zn}$ foil at current density equal range $\left(30\right.$ and $\left.35 \mathrm{~mA} / \mathrm{cm}^{2}\right)$. A relatively high peak intensity of the (101) miller indices at $2 \theta=36.35^{\circ}$ was observed, a $\mathrm{ZnO}$ peaks having much lower intensity were also detected at $2 \theta=\left(47.7^{\circ}, 56.56^{\circ}, 62.9^{\circ}, 68^{\circ}\right.$ and $\left.36.2^{\circ}\right)$ corresponding to the lattice miller indices (102), (110), (103), (112) and (201), respectively; sharp peaks confirmed the high degree of crystallinity hexagonal phase of prepared $\mathrm{ZnO}$ nanostructure. The crystal sizes $\left(\mathrm{G}_{\mathrm{S}}\right)$ of the $\mathrm{ZnO}$ films can be calculated using Scherer's formula [R. S. Dubey]: $D=k \lambda / \Delta_{(2 \theta)} \cos \theta$, where $\lambda, \theta$ and $B$ are the $\mathrm{X}$-ray wavelength $(0.154 \mathrm{~nm})$, the Bragg diffraction angle and the line-width at half-maximum of the (101) peak at around $\sim 44.4 \mathrm{~nm}$. The parameter was deduced from the XRD pattern. The values are found to be very much close to the standard values of hexagonal $\mathrm{ZnO}$. In a real $\mathrm{ZnO}$ crystal the hexagonal structure deviates from the ideal arrangement by changing the $c / a$ ratio or $u$ parameter. The lattice constants range from 3.234 to 3.244 for " $a$ " parameter and from 5.183 to 5.275 for " $c$ " parameter. The $c /$ $a$ ratio and $u$ parameter vary from 1.603 to 1.602 . The obtained XRD pattern has got good matching with others reported works [S. Kitova, R. S. Dubey] and standard JCPDS data (Number Card 36-1451). The chemical surface analysis images with different magnifications of $\mathrm{ZnO}$ nanostructures prepared using thermal oxidation at 15-20 kV.

The low-magnification scanning electron microscopy (FESEM) image which clearly shows that the whole $\mathrm{Zn}$ foil
Fig. 2 EDS of $\mathrm{ZnO}$ nanosheets grown on $\mathrm{Zi}$ foil substrate prepared by electrochemical method

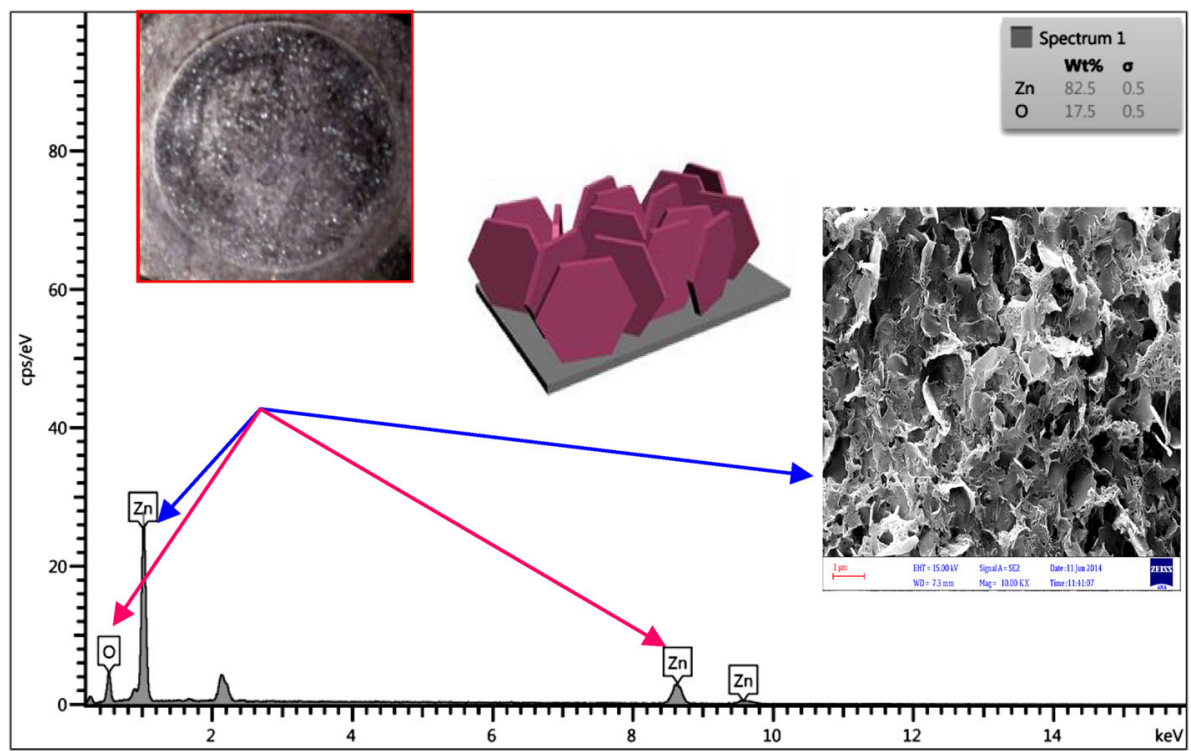



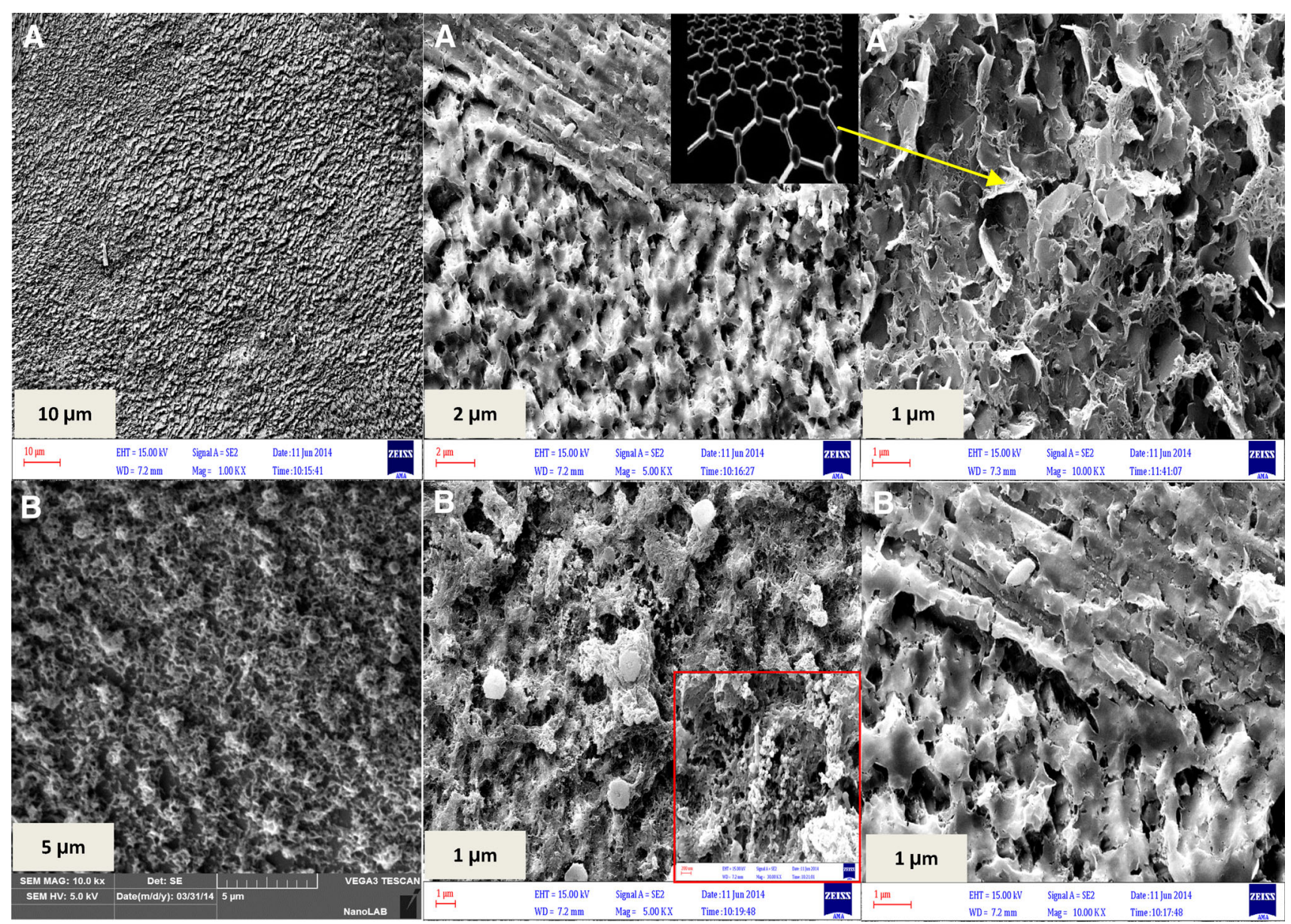

Fig. 3 FESEM images with different magnifications of zinc oxide nanosheets prepared at current density a $30 \mathrm{~mA} / \mathrm{cm}^{2}$ and b $35 \mathrm{~mA} / \mathrm{cm}^{2}$

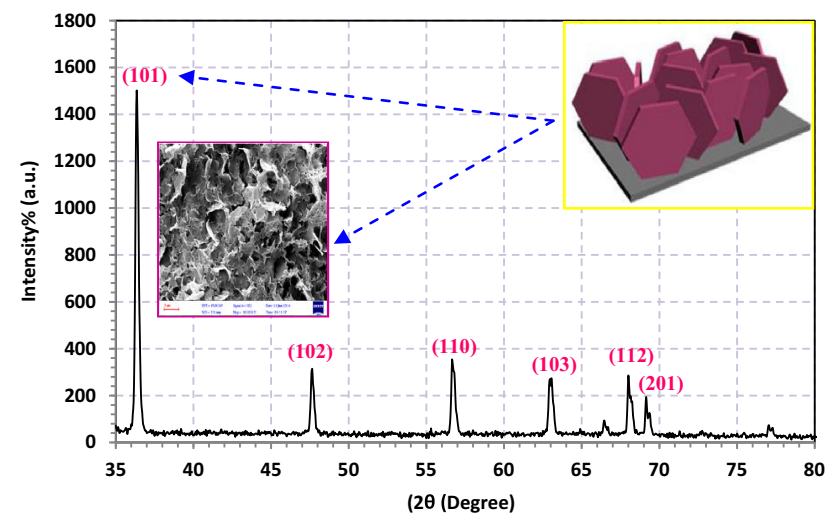

Fig. 4 XRD pattern of zinc oxide nanosheets prepared at current density $30 \mathrm{~mA} / \mathrm{cm}^{2}$

and rod substrate obtained $\mathrm{ZnO}$ nanotetrapods, nanorods and growth of nanoplane was also found are demonstrated in Fig. 5a-c at different oxidation temperature in the air for $5 \mathrm{~h}$ or less in static air. The length of these nanotetrapods and nanorods lies in the range of $1-1.5 \mu \mathrm{m}$ with an average diameter of $80 \mathrm{~nm}$. Figure 6 shows XRD patterns of $\mathrm{ZnO}$ nanotetrapods, nanorods and nanoplane were constructed using thermal oxidation method at different oxidation temperature $\left(700,800\right.$ and $\left.900{ }^{\circ} \mathrm{C}\right)$. The diffraction of higher intensity peaks at (002) miller indices with $2 \theta=34.435^{\circ}$ it can be recognized to a hexagonal wurtzite structure with lattice constants of $a=0.324 \mathrm{~nm}$ and $c=0.520 \mathrm{~nm}$, according to the card number (JCPDS 36-1451) and this result agreement with investigation paper [7-9]. No diffraction peaks arising from metallic $\mathrm{Zn}$ or any impurity were observed in all $\mathrm{ZnO}$ samples can be detected in the pattern confirms that the grown products are pure $\mathrm{ZnO}$ nanostructure at different condition. All the other peaks are in good agreement with the Joint committee on powder diffraction standard (JCPDS) data and the unit cell belonging to be hexagonal $\mathrm{ZnO}$ structure. The corresponding reflecting peak miller indices are (100), (002), (101), (102) and (110), respectively at different oxidation temperature in the tube furnace. At high oxidation temperature, it can recognize that the structures of $\mathrm{ZnO}$ samples are clearly improved where a significant increase in 


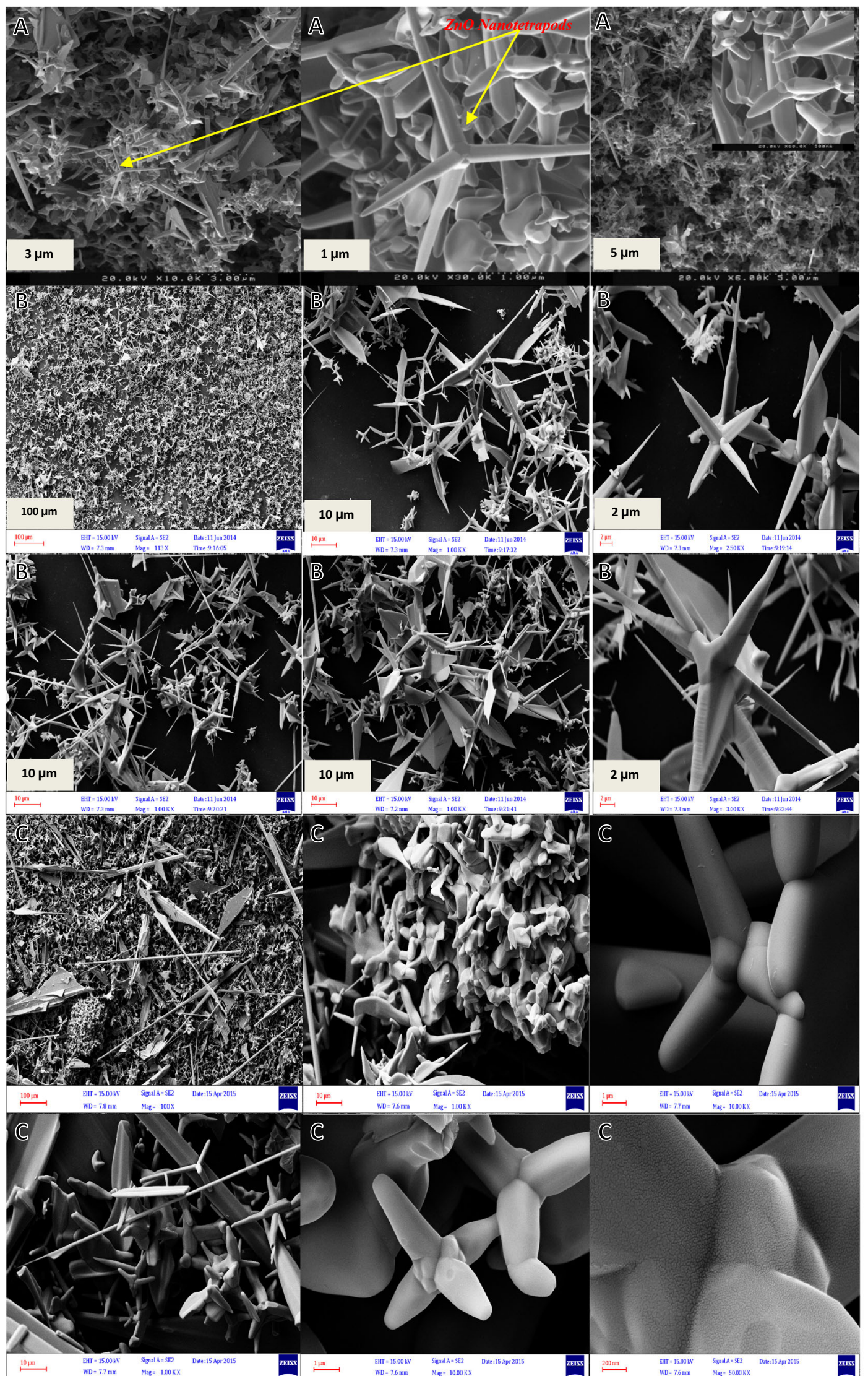

Fig. 5 FESEM of zinc oxide nanotetrapods, nanorods and nanoplane at different oxidation temperature a $700{ }^{\circ} \mathrm{C}, \mathbf{b} 800{ }^{\circ} \mathrm{C}$ and $\mathbf{c} 900{ }^{\circ} \mathrm{C}$ 
Fig. 6 XRD pattern of zinc oxide nanotetrapods, nanorods and nanoplane at different oxidation temperature a $700{ }^{\circ} \mathrm{C}$ b $800{ }^{\circ} \mathrm{C}$ and c $900{ }^{\circ} \mathrm{C}$

\section{Intensity (a.u.)}

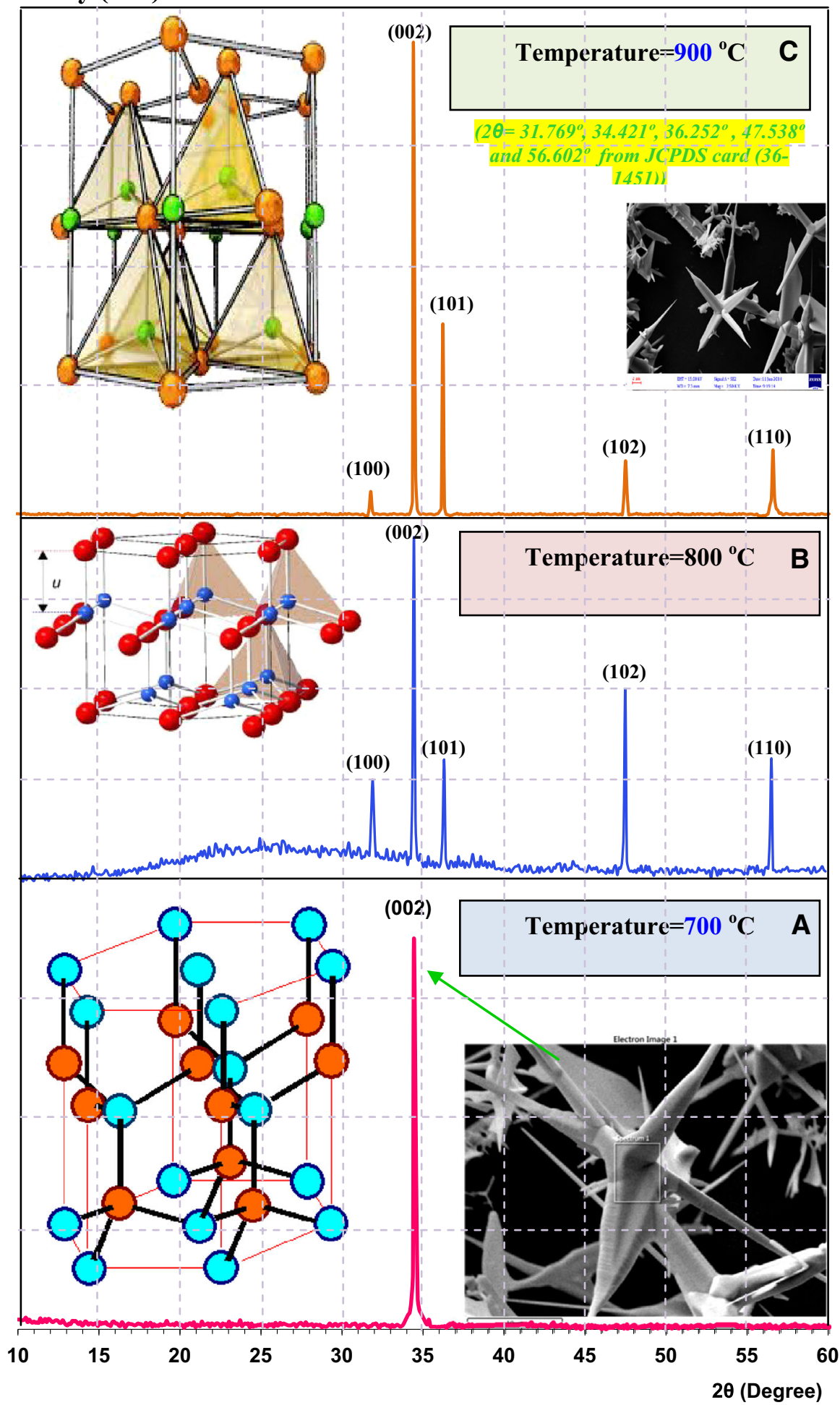

peak intensity at (002) miller indices can be attributed to the improvement in the structural order can also be attributed to the increase in the $\mathrm{ZnO}$ sample density, which results in demonstrated of (002) $\mathrm{ZnO}$ peak rather than other peak. This indicates the formation of nearly stoichiometry $\mathrm{ZnO}$ nanostructure.
The photoluminescence and crystal defects of $\mathrm{ZnO}$ nanotetrapods, nanorods and nanoplane prepared using thermal oxidation at different oxidation temperature in the tube furnace with $5 \mathrm{~h}$ or less in static air, photoluminescence spectrum curve was measured and the typical spectrum curve is shown in Fig. 7. $\mathrm{ZnO}$ crystal 


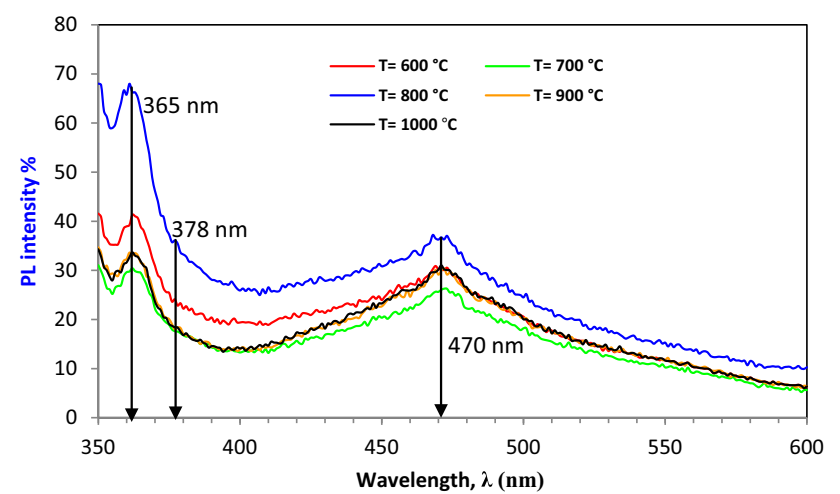

Fig. 7 PL of zinc oxide nanostructure at different oxidation temperature with $5 \mathrm{~h}$

displays two emission peaks when excited with UV light. The position of strong peak was observed at about $363 \mathrm{~nm}$ called UV luminescence band, and the green emission, the very broad, weak peak was located at $470 \mathrm{~nm}$, which revealed the existence of a low concentration of oxygen vacancies called green luminescence band. The near band edge emission corresponding peak at $378 \mathrm{~nm}$, related to the direct recombination of photogenerated electron-hole pairs between the $\mathrm{ZnO}$ optical band gaps [10].

It can be seen that the green emission broadening refers to the defects in the sample, and green peaks have a shift towards blue shift indicating $\mathrm{ZnO}$ nanostructures, this agrees with the XRD and SEM results.

\section{Conclusions}

$\mathrm{ZnO}$ nanosheets, nanotetrapods, nanorods and nanoplane were grown on $\mathrm{Zn}$ foil using different methods (electrochemical deposition and thermal oxidation) with different conditions. XRD, FESEM and PL were investigated in this work.
Open Access This article is distributed under the terms of the Creative Commons Attribution 4.0 International License (http:// creativecommons.org/licenses/by/4.0/), which permits unrestricted use, distribution, and reproduction in any medium, provided you give appropriate credit to the original author(s) and the source, provide a link to the Creative Commons license, and indicate if changes were made.

\section{References}

1. Taabouche, A., Bouabellou, A., Kermiche, F., Hanini, F., Menakh, S., Bouachiba, Y., Kerdja, T., Benazzouz, C., Bouafia, M., Amara, S.: Effect of substrates on the properties of $\mathrm{ZnO}$ thin films grown by pulsed laser deposition. Adv. Mater. Phys. Chem. 3, 209-213 (2013)

2. Lau, S.P., Yang, H.Y., Yu, S.F., Li, H.D., Tanemura, M., Okita, T., Hatano, H., Hng, H.H.: Laser action in $\mathrm{ZnO}$ nanoneedles selectively grown on silicon and plastic substrates. Appl. Phys. Lett. 87, 013104 (2005)

3. Sun, Y., Riley, D.J., Ashfold, M.N.R.: Mechanism of ZnO nanotube growth by hydrothermal methods on $\mathrm{ZnO}$ film-coated $\mathrm{Si}$ substrates. J. Phys. Chem. B. 110, 15186-15192 (2006)

4. Samanta, P.K., Patra, S.K., Ghosh A., Chaudhuri, P.R.: Visible emission from $\mathrm{ZnO}$ nanorods synthesized by a simple wet chemical method. Int. J. Nanosci. Nanotechnol. 1(1-2), 81-90 (2009)

5. Cao, B., Cai, W.: From $\mathrm{ZnO}$ nanorods to nanoplates: chemical bath deposition growth and surface-related emissions. J. Phys. Chem. C 112, 680-685 (2008)

6. George, A., Kumari, P., Soin, N., Roy, S.S., McLaughlin, J.A.: Microstructure and field emission characteristics of $\mathrm{ZnO}$ nanoneedles grown by physical vapor deposition. Mater. Chem. Phys. 123, 634-638 (2010)

7. Wu, X., Bai, H., Li, C., Lu, G., Shi, G.: Controlled one-step fabrication of highly oriented $\mathrm{ZnO}$ nanoneedle/nanorods arrays at near room temperature. Chem. Commun. 21(15):1655-1657 (2006)

8. Kumar, S., Gupta, V., Sreenivas, K.: Synthesis of photoconducting $\mathrm{ZnO}$ nano-needles using an unbalanced magnetron sputtered $\mathrm{ZnO} / \mathrm{Zn} / \mathrm{ZnO}$ multilayer structure. Nanotechnology 16, 1167-1171 (2005). doi:10.1088/0957-4484/16/8/031

9. Senthil Kumar, M., Chhikara, D., Srivatsa, K.M.K.: Structurecontrolled growth of $\mathrm{ZnO}$ nanonails by thermal evaporation technique. Cryst. Res. Technol. 46(9), 991-996 (2011). doi:10. 1002/crat.201100141

10. Feng, W., Chen, J., Hou, C.: Growth and characterization of $\mathrm{ZnO}$ needles. Appl. Nanosci. (2014). doi:10.1007/s13204-012-0174-9 